\title{
Plant Growth Promotion of Rice as Influenced by Ochrobactrum sp. (MH685438) a Rhizospheric Bacteria Associated with Oryzae sativa
}

\author{
M.S. Vidhyasri", V. Gomathi and U. Siva Kumar \\ Department of Agricultural Microbiology, Tamil Nadu Agricultural University, \\ Coimbatore- 641 003, Tamil Nadu, India \\ *Corresponding author
}

Keywords

PEG, Drought

stress,

Ochrobactrum sp.

(MH685438),

Oryzae sativa

Article Info

Accepted:

10 April 2019

Available Online:

10 May 2019

\section{A B S T R A C T}

Plants subjected to different environmental stresses, of which drought is a major abiotic stress constraint for crop production. Current study, investigated the adverse effects of drought stress on growth and modulation of root system architecture of rice inoculated with drought-tolerant bacteria Ochrobactrum sp. (MH685438). Polyethylene glycol (PEG) solutions of different concentrations $(5 \%, 10 \%, 15 \%, 20 \%, 25 \% \& 30 \%)$ were used for drought stress induction artificially. It was observed that growth of bacteria significantly reduced under drought stress, while maximum reduction was caused by PEG (30\%) applied. Drought-tolerant bacteria Ochrobactrum sp. (MH685438) identified based on 16S rDNA gene sequence was used to study the effect on drought stress tolerance of rice growth. Rice plants inoculated with Ochrobactrum sp. (MH685438) showed potential to withstand the drought upto $30 \%$ of PEG, also increased the plant shoot and root length when compared to control. The bacterium also improved the germination percentage of rice seeds at different concentration of PEG 6000. Current investigation concluded that application of Ochrobactrum sp. (MH685438) may increase the tolerance capacity of crop plants especially rice against drought.

\section{Introduction}

Abiotic stress is a major constrain which can adversely affect the plant growth and productivity. Plants are exposed to number of potentially adverse environmental conditions such as water deficit, high salinity, extreme temperature, and submergence. In response, plants have evolved delicate mechanisms, from the molecular to the physiological level, to adapt to stressful environments. Drought is a situation where water potential and the turgor of plant leaf cells reduces to a level where normal functions are impaired. It causes stomatal closure and limits gas exchange, reduces water content, turgor, water potential and results in wilting of the plant (Shao et al., 2008). Detrimental effects caused by different abiotic stresses are related to disruption of plant water status in one or the other way. The field drought condition can manifest physiological changes similar to other abiotic stresses like high temperature, disturbed ion intake and nutrient deficiencies in plants (Wang et al., 2003). Verslues et al., (2006) have comprehensively described the 
physiological changes and stages of the drought response.

Plant growth promoting bacteria (PGPB) can mitigate the impact of abiotic stresses on plants through a process called induced systemic tolerance (IST), which includes bacterial production of cytokinins, production of antioxidants and degradation of the ethylene precursor 1- aminocyclopropane-1carboxylate (ACC) by bacterial ACC deaminase. Rhizosphere colonizing bacteria were well studied for their role in stress tolerance (Sandhya et al., 2011), but few studies were focused on phyllosphere bacterial amelioration of abiotic and biotic stress in plants.

Rice is the staple food for more than half of the world's population. Evolved in a semiaquatic, low-radiation habitat, rice exhibits distinct tolerance and susceptibilities to abiotic stresses among domesticated cereal crops (Lafitte et al., 2004). Substantial areas under rice cultivation in the tropics and subtropics are affected by drought. Plant productivity is considerably reduced due to improper nutrition of plants plus the osmotic and drought stress (Munn et al., 1993).Rice is affected by drought stress at each developmental stage in all rice growing ecosystems and the crop responds differently to the drought stress in different life stages (Boonjung and Fukai, 1996).

Plants deploy drought avoidance mechanisms including leaf rolling, stomatal closure, reduced tillering and accumulation of osmoprotectants to prevent severe damage caused due to drought (Hadiarto and Tran, 2011). The effect of vegetative drought stress in upland rice results in reduced tiller number and reduced panicles, whereas drought stress during the reproductive growth phases cause heavy yield losses (Boonjung and Fukai, 1996).
The rhizobacteria assemblages of many agricultural crops have been studied, and the use of PGPR holds promise for plant growth promotion and alleviation of plant drought stress (Mayak et al., 2004; Zahir et al., 2008; Sandhya et al., 2009). However, the droughttolerant bacteria associated with crop species which are naturally adapted to drought, such as rice, have not been explored.

Ochrobactrum species have been described as free-living Alphaproteobacteria, and have been recovered from diverse habitats, including soil, plants and their rhizospheres, animals, and humans. In soil, Ochrobactrum strains were found to constitute $2 \%$ of the cultivable bacteria, and on the wheat rhizoplane this fraction was approximately 0.3\% (Lebuhn et al., 2000; Bathe et al., 2004), indicating that Ochrobactrum is a substantial part of the currently cultivable soil and rhizosphere microbial communities. The diazotrophy of Ochrobactrum, strains with complete symbiotic ability in Acacia and Lupinus nodules (Ngom et al., 2004; Trujillo et al., 2005). In addition to its ability to establish symbiotic relationships with legumes, some species of the genus Ochrobactrum, as is the case of $O$. antrhopi, have been described as PGPR. Stenotrophomonas and Ochrobactrum strains have been isolated from various sources, mainly plant rhiospheres and aquatic habitat (Imran et al., 2010; Hanssan et al., 2010). Yousuf et al., (2012) has reported the presence of strains of the Ochrobactrum genus in A. hypogaea rhizospheres. In present study, Ochrobactrum sp. (MH685438) have been isolated from rice rhizosphere and investigated for its ability to improve the plant growth and to mitigate drought stress on rice. The application of plant-growth-promoting bacteria (PGPB) is an alternative strategy for improving plant fitness under stressful conditions. 


\section{Materials and Methods}

\section{Bacterial strain and assessment of drought stress tolerance}

The rice rhizosphere isolate Ochrobactrum sp. (MH685438) was selected for the study. The aforementioned isolate was previously isolated from the rhizosphere of rice and confirmed for its plant growth promoting characteristics.

The drought stress tolerance of selected isolate was tested using polyethylene glycol (PEG). The susceptibility of the selected bacteria in presence of PEG was relatively unknown. $1 \mathrm{~mL}$ of the bacterial culture was added to the test-tubes containing $70 \mathrm{~mL}$ of nutrient media amended with varying PEG concentrations $(0 \%, 5 \%, 10 \%, 15 \%, 20 \%$, $25 \%$ and $30 \%$ ) for assessing the drought sustaining capacity of the isolate. All testtubes were incubated on shaker at $28 \pm 2{ }^{\circ} \mathrm{C}$ for 5 days. Bacteria growth viability under stress was monitored over the period of 5 days by measuring the optical density at $600 \mathrm{~nm}$.

\section{In vitro assessment of plant growth of rice under induced drought stress}

The drought tolerant Ochrobactrum sp. (MH685438) was used to evaluate the potential in alleviating drought-stress effects in host plant rice (Oryzae sativa) as described by Sandhya et al., (2009). Seeds were surface sterilized and colonized with $\left(10^{8}\right.$ cells $\left./ g\right)$ of drought tolerant Bacillus strain, shade dried and sown in germination sheet (sterilized). In vitro screening for drought tolerance was carried out using Polyethylene Glycol (PEG $6000 \mathrm{MW}$ ). In germination paper, a horizontal line was drawn at $3 \mathrm{~cm}$ from the top and was marked with 25 points at $1 \mathrm{~cm}$ intervals. Twenty five seeds were placed in the marked point on the moistened paper towel, ensuring that the seeds do not touch each other and a moistened second paper towel was carefully placed over the seeds. The paper towels along with a polythene sheet below it were then rolled loosely to form a tube and held with rubber band. The rolls were placed in the containers of different PEG concentration. Drought stress was stimulated using different concentrations viz., 5\%, 10\%, 15\%, 20\%, $25 \%$ and $30 \%$ of PEG 6000 respectively in 70 $\mathrm{ml}$ of Hoagland's nutrient solution. A control (0.0 bar) was maintained using sterile distilled water. The whole experimental set up was provided with light and dark at $12 \mathrm{~h}$ intervals. Water stressed seedlings and their corresponding unstressed controls were observed after 15 days of exposure to drought for germination percentage, root length, shoot length and root/shoot ratio at six different levels of treatment. The experiment was laid in completely randomized design with three replications.

\section{Results and Discussion}

Survival efficacy of Ochrobactrum sp. (MH685438) in response to induced drought by polyethylene glycol (PEG)

The selected bacterial isolate Ochrobactrum sp. (MH685438) was tested for the drought sustaining capacity in the presence of different PEG concentrations (0\% to 30\%). Based on the growth pattern it was shown that the bacterial isolate Ochrobactrum sp. (MH685438) was able to grow up to $30 \%$ PEG concentration (-1.32 bars of Osmotic Potential) (Table 1).

Ochrobactrum sp. (MH685438) isolate has higher drought tolerance compared to standard culture (MTCC 453- drought tolerant), which sustains up to the osmotic potential of -1.32 bars pressure (30\% PEG Conc.) and higher growth rate was recorded $(0.51 \pm 0.007 \mathrm{OD})$, whereas standard culture 
has the potential of tolerating up to $15 \%$ PEG concentrations $(0.58 \pm 0.007$ OD) afterwards the growth was declined. Ochrobactrum sp. (MH685438) screened for drought tolerance could tolerate minimal water potential $(-1.32$ MPa). Similarly, Paulucci et al., (2015), isolated and screened the osmotic stresstolerant ACC deaminase-producing bacterial Ochrobactrum pseudogrignonense RJ12, and their PGP activities were evaluated in black gram and garden pea plants under water deficit conditions. Mishra et al., (2017) reported that NBRISH6 (Ochrobactrum sp.) can withstand drought upto $60 \%$ and with maximum $\mathrm{CFU}$ in vitro under abiotic stress (drought) suggests that it may resist fluctuations under natural conditions too and therefore, presumably promote plant growth in vivo.

Effect of Ochrobactrum sp. (MH685438) on germination percentage, root and shoot length and vigor index of rice seedlings under water stress

Germination of rice seedlings was decreased with the increasing concentration of PEG viz., 0 to $30 \%$. However, the effect of PEG was greatly reduced in rice seeds treated with bacterial cultures viz., Ochrobactrum sp. (MH685438) and standard culture (MTCC 453). Among the isolates tested, Ochrobactrum sp. (MH685438) greatly enhanced the germination percentage at -1.32 OP $(58 \%)$ levels of PEG compared to uninoculated control (16\%). According to the study of Lum et al., (2014) drought-tolerant variety of paddy, Pulot Wangi tolerated PEG at the highest drought level (-8 bar) and showed no significantly difference relation to control. However, drought-sensitive variety, Kusam was markedly affected even at the lowest drought level used. In the current study we are using rice variety (CO 51) it was tolerated up to -1.32 bars of Osmotic Potential with the aid of Ochrobactrum sp.
(MH685438) inoculation. Vardharajula et al., (2011) studied the effect of seed inoculation of drought-tolerant Bacillus spp. strains on the growth and physiological and biochemical status of the maize seedlings exposed to drought stress. Drought stress drastically affected the growth of maize as reflected by stunted growth, less vigour, and wilting of leaves. However, inoculated plants survived up to 9 days after exposure to drought stress, respectively and started wilting thereafter (Fig. 1).

Effect of Ochrobactrum sp. (MH685438) on root length of rice seedlings under water stress

The Ochrobactrum sp. (MH685438) inoculated treatment showed significantly higher plant growth in terms of root and shoot length (Table 2 and 3), and vigour index (Table 4) as compared to standard and uninoculated control under both drought stress as well as non stress conditions.

Root length was decreased as the concentration of PEG increased, viz., 0 to 30 $\%$. However, culture treated seeds recorded better root growth than the uninoculated control at all concentrations of PEG. At higher concentration of PEG (30\%), Ochrobactrum sp. (MH685438) treated seeds showed $7.05 \mathrm{~cm}$ root length followed by standard strain treated seeds $(4.90 \mathrm{~cm})$ whereas uninoculated control showed only $2.0 \mathrm{~cm}$ root length (Table 2). It is clear from the data recorded that our isolate Ochrobactrum sp. (MH685438) exhibited profound effect on paddy growth under water stress condition. Similarly, Mishra et al., (2017), observed that, Ochrobactrum sp. NBRISH6 bacterial treatment to the plant showed 44\% increase in Root length, fresh root $(97 \%)$ and dry root (94\%) weight in maize. Yasmin et al., (2013) also reported that under drought stress, maize plants 
inoculated with PGPR isolate enhanced root length by $43.3 \%$. Naveed et al., (2014) reported that maize plants inoculated with Burkholderia phytofirmans strain PsJN had significantly increased root biomass by 70 and $58 \%$ in Mazurka and Kaleo cultivars respectively.

Effect of Ochrobactrum sp. (MH685438) on the shoot length of rice seedlings under water stress

One of the key responses to drought stress is the inhibition of shoot growth, which benefits plants by limiting the leaf area available for evaporative loss of limited water reserves (Skirycz and Inze, 2010). In addition, inhibiting shoot growth allows plants to divert essential solutes from growth requirements to stress-related house-keeping functions, such as osmotic adjustment. Therefore, inhibition of shoot growth is considered an adaptive response that helps plants to tolerate drought stress (Aachard et al., 2006). Hence, inhibition of shoot growth could be a counterproductive response in the case of crop plants exposed to moderate drought stress (Neumann, 2008). However treatment of plants with PGPR typically increases shoot growth, under drought stress and plants inoculated with effective PGPR strains could maintain near-normal shoot growth rates, resulting in increased crop productivity.

Our results also have close relation with the above said hypothesis and the Ochrobactrum treated plants recorded higher shoot length compared to control non stressed plants. This result implies that Ochrobactrum inoculation might counteract or nullify the effect of moisture stress. In this study, under drought stress conditions, the plants inoculated with the tested Ochrobactrum sp. (MH685438) showed significantly increased shoot length of $(11.05 \mathrm{~cm})$ when compared to standard strain $(6.90 \mathrm{~cm})$ and control $(2.0 \mathrm{~cm})$. Similarly, Mishra et al., (2017) reported that, Ochrobactrum sp. NBRISH6 treatment to the maize plant showed 56\% increase in shoot length, shoot fresh (144\%) and dry weight (157\%). Timmusk et al., (2014) showed that under drought stress, wheat plants treated with PGPR had $78 \%$ higher biomass than non-treated plants, confirming the potential of PGPR to enhance plant performance under drought stress.

\section{Effect of Ochrobactrum sp. (MH685438) on the vigor index of rice seedlings under water stress}

Vigor index is the most one of the important traits pertaining to seed quality and seedling establishment in the field to be closely related to the vigor index assessed in lab scale experiments. Various studies proved that vigor index was improved by microbial inoculation. According to Sariah et al., (2011) bacterization of rice seeds with E. gergoviae and $B$. amyloliquefaciens gave significantly high seed vigor index of 247.60 and 237.84, respectively.

Table.1 Growth rate of Ochrobactrum sp. (MH685438) with increasing concentrations of PEG $6000(\mathrm{OD}$ at $600 \mathrm{~nm})$

\begin{tabular}{|c|c|c|c|c|c|c|c|}
\hline Bacterial strain & $\mathbf{0 \%}$ & $\mathbf{5 \%}$ & $\mathbf{1 0 \%}$ & $\mathbf{1 5 \%}$ & $\mathbf{2 0 \%}$ & $\mathbf{2 5 \%}$ & $\mathbf{3 0 \%}$ \\
\hline Ochrobactrum & 1.35 & 1.15 & 1.04 & 0.72 & 0.75 & 0.68 & 0.51 \\
sp. (MH685438) & $(0.028)$ & $(0.012)$ & $(0.008)$ & $(0.004)$ & $(0.014)$ & $(0.004)$ & $(0.007)$ \\
\hline $\begin{array}{c}\text { Bacillus } \\
\text { megaterium } \\
\text { (MTCC 453) }\end{array}$ & 1.10 & 0.96 & 0.69 & 0.58 & 0.08 & 0.15 & 0.01 \\
& & $(0.016)$ & $(0.004)$ & $(0.007)$ & $(1.02)$ & $(0.001)$ & $(0.001)$ \\
\hline
\end{tabular}

Values in the parenthesis are mean \pm standard error of seven replicates. PEG 
Table.2 Effect of Ochrobactrum sp. (MH685438) on the root length of rice seedlings under induced drought

\begin{tabular}{|c|c|c|c|}
\hline \multirow{2}{*}{ PEG Conc. } & \multicolumn{3}{|c|}{ Root length $(\mathbf{c m})$} \\
\cline { 2 - 4 } & L1 & L2 & L3 \\
\hline $\mathbf{T}_{\mathbf{1}} \mathbf{0}$ \% PEG & 15.50 & 13.90 & 9.50 \\
\hline $\mathbf{T}_{\mathbf{2}}-\mathbf{5} \%$ PEG & 14.30 & 12.50 & 8.50 \\
\hline $\mathbf{T}_{\mathbf{3}}-\mathbf{1 0} \%$ PEG & 11.85 & 9.10 & 7.80 \\
\hline $\mathbf{T}_{\mathbf{4}}-\mathbf{1 5} \%$ PEG & 12.00 & 11.70 & 7.05 \\
\hline $\mathbf{T}_{\mathbf{5}}-\mathbf{2 0} \%$ PEG & 11.95 & 8.20 & 5.75 \\
\hline $\mathbf{T}_{\mathbf{6}}-\mathbf{2 5} \%$ PEG & 9.00 & 6.05 & 3.05 \\
\hline $\mathbf{T}_{\mathbf{7}}-\mathbf{3 0} \%$ PEG & 7.05 & 4.90 & 2.0 \\
\hline SEd & 1.094 & 1.273 & 1.060 \\
\hline C.D $(\mathbf{0 . 0 5})$ & 0.019 & 0.018 & 0.190 \\
\hline
\end{tabular}

L1 - Ochrobactrum sp. (MH685438)., L2 - Standard (MTCC 453), L3- Control

Table.3 Effect of Ochrobactrum sp. (MH685438) on the shoot length of rice seedlings under induced drought

\begin{tabular}{|c|c|c|c|}
\hline \multirow{2}{*}{ PEG Conc. } & \multicolumn{3}{|c|}{ Shoot length (cm) } \\
\cline { 2 - 4 } & L1 & L2 & L3 \\
\hline $\mathbf{T}_{\mathbf{1}} \mathbf{0}$ \% \% PEG & 26.85 & 22.65 & 12.70 \\
\hline $\mathbf{T}_{\mathbf{2}}-\mathbf{5} \%$ PEG & 26.00 & 18.95 & 11.40 \\
\hline $\mathbf{T}_{\mathbf{3}}-\mathbf{1 0} \%$ PEG & 24.95 & 15.85 & 10.75 \\
\hline $\mathbf{T}_{\mathbf{4}}-\mathbf{1 5} \%$ PEG & 22.85 & 13.85 & 9.30 \\
\hline $\mathbf{T}_{\mathbf{5}}-\mathbf{2 0} \%$ PEG & 18.60 & 12.55 & 8.95 \\
\hline $\mathbf{T}_{\mathbf{6}}-\mathbf{2 5} \%$ PEG & 14.05 & 10.00 & 6.05 \\
\hline $\mathbf{T}_{\mathbf{7}} \mathbf{- 3 0 \%}$ PEG & 11.05 & 6.90 & 2.0 \\
\hline SEd & 2.342 & 2.013 & 1.379 \\
\hline C.D(0.05) & 0.017 & 0.016 & 0.068 \\
\hline
\end{tabular}

L1 - Ochrobactrum sp. (MH685438), L2 - Standard (MTCC 453), L3- Control

Fig.1 Effect of Ochrobactrum sp. (MH685438) on germination percentage of rice seedlings under water stress condition

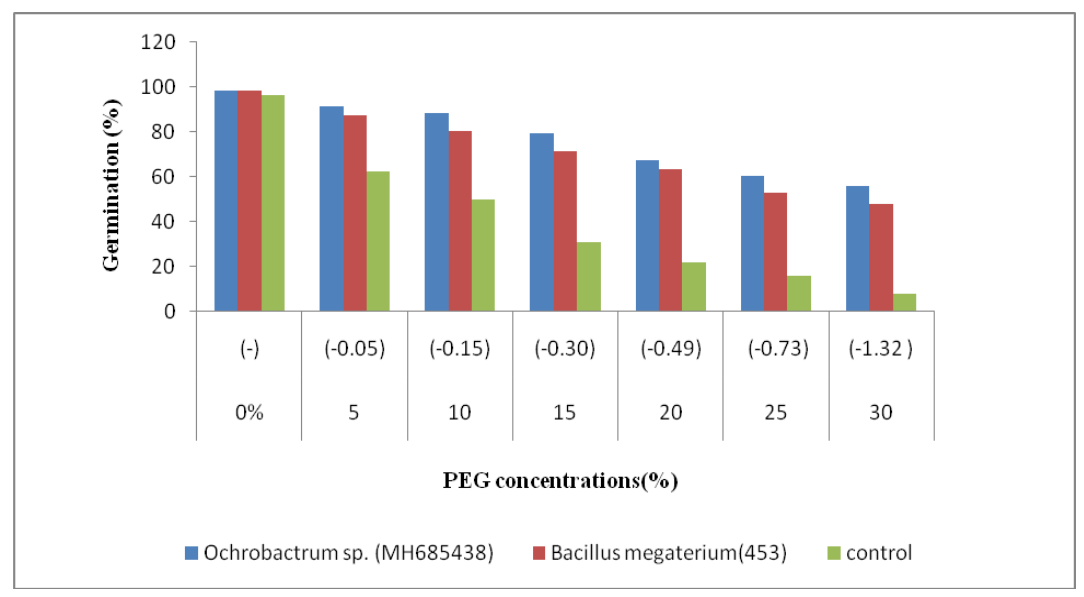


Fig.2 Effect of Ochrobactrum sp. (MH685438) on the vigor index of rice seedlings under induced drought

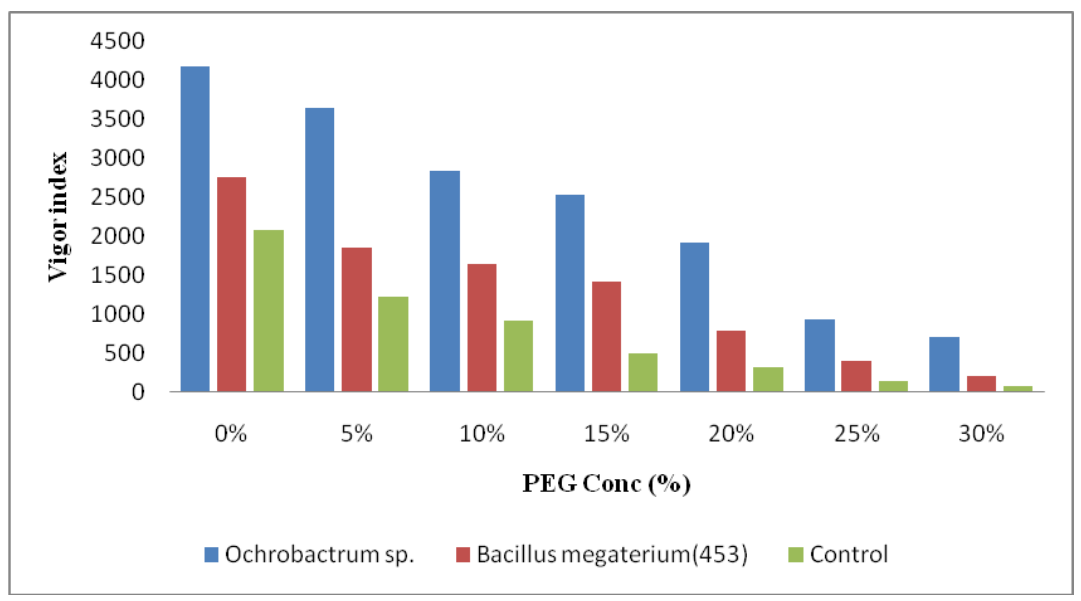

In the present investigation vigor index of rice under moisture stress condition was improved by Ochrobactrum sp. (MH685438) inoculation (4171 to 708 from 0 - 30\% PEG) compared to standard strain (2755 to 204 from $0-30 \%$ PEG) as well as control (2086 to 85 from 0 - 30\% PEG) (Fig. 2). Vigor index were declined with increasing PEG concentrations irrespective of the treatments, however Ochrobactrum sp. (MH685438) inoculation improves better compared to control. Batool et al., (2014) compared the two varieties of maize in response to the water stress condition and the results indicated that seeds treated with diazotrophic bacteria, Pseudomonas spp.

\section{Conclusion}

PGPR may help plants tolerate drought stress via the enhancement and alteration of root parameters. From the present investigation, it was concluded that the isolate Ochrobactrum sp. (MH685438) has higher drought sustaining capacity and growth promoting activity compared to standard strain under induced moisture stress condition. Hence Ochrobactrum sp. (MH685438) proved to have a promising role in improving plant performance under drought condition.

\section{Acknowledgement}

The authors are grateful to the Ministry of Human Resources Development (MHRD), New Delhi for providing financial assistance to undertaking this research.

\section{References}

Achard, S., R. Salvador, B.Whitcher, J. Suckling, and E. Bullmore. 2006. A resilient, low-frequency, small-world human brain functional network with highly connected association cortical hubs. J. Neurosci. 26, 63-72

Bathe, S, M. Lebuhn, J. Ellwart, S. Wuertz, M. Hausner. 2004. High phylogenetic diversity of transconjugants carrying plasmid pJP4 in an activated sludgederived microbial community. FEMS Microbiol Lett. 235:215-9.

Batool N, Shahzad A, Ilyas N, Noor T .2014. Plants and Salt stress. Int J Agri Crop Sci. 7 (9): 582-589.

Bewley, J. D. 1979. Physiological aspects of desiccation tolerance. Annual review of plant physiology, 30(1), pp.195238.

Boonjung, H. and S. Fukai. 1996. Effects of soil water deficit at different growth 
stages on rice growth and yield under upland conditions. 2. Phenology, biomass production and yield. Field Crops Research, 48(1), pp.47-55.

Hadiarto, T. and L.-S. P. Tran. 2011. Progress studies of drought-responsive genes in rice. Plant cell reports, 30(3), pp.297310.

Imran A, Hafeez F, Frühling A, Schumann P, Malik K, Stackebrandt E. Ochrobactrum ciceri sp. nov., isolated from nodules of Cicer arietinum. Int $\mathbf{J}$ Syst Evol Microbiol., 2010; 60: 154853.

Lafitte H.R., A. Ismail and J. Bennett. 2004. Abiotic stress tolerance in rice for Asia: progress and the future. New Directions for a Diverse Planet. Proceedings for the 4th International Crop Science Congress, Brisbane, Australia, 26 September-1 October 2004.

Lebuhn M, W. Achouak, M. Schloter, O. Berge, H. Meier, M. Barakat. 2000. Taxonomic characterization of Ochrobactrum sp. isolates from soil samples and wheat roots,and description of Ochrobactrum tritici sp. nov. and Ochrobactrum grignonense sp. nov. Int J Syst Evol Microbiol; 50: 2207-23.

Lum , M., M. Hanafi , Y. M. Rafii, and A. S. N. Akmar. 2014. Effect of drought stress on growth, proline and antioxidant enzyme activities of upland rice. The Journal of Animal \& Plant Sciences, 24(5): Page: $1487-$ 1493.

Malik, K.A., G. Rasul, U. Hassan, S. Mehnaz, M. Asharaf, in: N.A. Hegazi, M. Fauez, M. Monib (Eds.), Nitrogen fixation with nonlegumes. 1993. The Am. Univ. in Cairo Press, Cairo, pp. 409-422.

Mishra, S. K. M.H. Khan . S. Misra. V. K. Dixit, K. Praveen . S. Srivastava. C.
Puneet. 2017. Characterisation of Pseudomonas spp. and Ochrobactrum $s p$. isolated from volcanic soil Antonie van Leeuwenhoek. 110:253-270

Munn. R. 1993. Physiological processes limiting plant growth in saline soils: Some dogmas and hypotheses, Plant Cell Environ. 16 pp. 15-24.

Naveed, M., Mitter, B., Reichenauer, T.G., Wieczorek, K. and Sessitsch, A. 2014. Increased drought stress resilience of maize through endophytic colonization by Burkholderia phytofirmans PsJN and Enterobacter sp. FD 17. Environ. Exp. Bot. 97, 3039.

Neumann, P.M. 2008. Coping mechanisms for crop plants in drought-prone environments. Ann. Bot. 101, 901907.

Ngom, A., Y. Nakagawa, H. Sawada, J. Tsukahara, S. Wakabayashi, T. Uchiumi. 2004. A novel symbiotic nitrogen-fixing member of the Ochrobactrum clade isolated from root nodules of Acacia mangium. J Gen Appl Microbiol., 50:17-27

Ping. S.Z., M. Lin, C.B. You and K.A. Malik. 1996. Salt tolerance of diazotroph Alcaligenes faecalis and its interaction with host rice under salt stress, J. Agric. Biotechnol. 4 pp. 87-92.

Sandhya V., Ali SKZ, Minakshi G., Gopal Reddy. and Venkateswarlu B. 2009. Alleviation of drought stress effects in sunflower seedlings by the exopolysaccharides producing Pseudomonas putida strain GAP-P45. Biol Fertil Soils. 46: 1726.

Sandhya V., Ali Z, Grover M., Reddy G. and Bandi V. 2011. Drought tolerant plant growth promoting Bacillus spp.: effect on growth, osmolytes, and antioxidant status of maize under drought stress. J. Plant Interact. 6: 1-14.

Sariah M, Paterson R.R.M, Zainal Abidin 
M.A and Lima, N. 2011. Ergosterol analyses of oil palm seedlings and plants infected with Ganoderma. Crop Protect. 30:1438-1442

Shao, H., L. Chu, C. Jaleel and C. Zhao. 2008. Water-deficit stress-induced anatomical changes in higher plants. Comptes Rendus Biologies, 331(3), pp.215-225.

Skirycz, A. and Inzé, D., 2010. More from less: plant growth under limited water. Curr. Opin. Biotechnol. 21, 197-203.

The Regional Institute Ltd. http://www.cropscience.org.au/ icsc2004

Timmusk, S., Abd El-Daim, I.A., Copolovici, L., Tanilas, T., Kannaste, A., Behers, L, and Niinemets, U., 2014. Droughttolerance of wheat improved by rhizosphere bacteria from harsh environments: enhanced biomass production and reduced emissions of stress volatiles. PLoS One 9, e96086.

Trujillo M., A. Willems, A. Abril, A. Planchuelo, R.Rivas, D. Lude na. 2005. Nodulation of Lupinus albus by strains of Ochrobactrum lupine sp. nov. Appl Environ Microbiol; 71:1318-27.

Ueda. T. ., Y. Surga, N. Yohiroe, T. Matsuguchi. 1995. Remakable N2fixing bacterial diversity detected in the rice roots by molecular evolutionary analysis of nifH gene sequences, J. Bacteriol. 177 14141417

Vardharajula, S., Ali, S.Z., Grover, M., Reddy, G. and Bandi. V. 2011. Drought-tolerant plant growth promoting Bacillus spp.: effect on growth osmolytes, and antioxidant status of maize under drought stress. J. Plant Interact. 6, 1-14.

Verslues, P. E., M. Agarwal, S. KatiyarAgarwal, J. Zhu and J.-K. Zhu. 2006. Methods and concepts in quantifying resistance to drought, salt and freezing, abiotic stresses that affect plant water status. The Plant Journal, 45(4), pp. 523-539.

Wang, W., B. Vinocur and A. Altman. 2003. Plant responses to drought, salinity and extreme temperatures: towards genetic engineering for stress tolerance. Planta, 218(1), pp.1-14.

Yasmin, H., Bano, A. and Samiullah, A. 2013. Screening of PGPR isolates from semi-arid region and their implication to alleviate drought stress. Pak. J. Bot. 45, 51-58.

Yousuf B, Keshri J, Mishra A, Jha B. Application of targeted metagenomicsto explore abundance and diversity of $\mathrm{CO}_{2}$-fixing bacterial community using $c b b L$ gene from the rhizosphere of Arachis hypogaea. Gene 2012; 506: 18-24.

\section{How to cite this article:}

Vidhyasri, M.S., V. Gomathi and Siva Kumar, U. 2019. Plant Growth Promotion of Rice as Influenced by Ochrobactrum sp. (MH685438) a Rhizospheric Bacteria Associated with Oryzae sativa. Int.J.Curr.Microbiol.App.Sci. 8(05): 901-909.

doi: https://doi.org/10.20546/ijcmas.2019.805.105 